\title{
Understanding the variability of water isotopologues in near-surface atmospheric moisture over a humid subtropical rice paddy in Tsukuba, Japan
}

\author{
Wei Zhongwang,b,b, Kei Yoshimura ${ }^{\mathrm{b}, \mathrm{c}}$, Atsushi Okazaki ${ }^{\mathrm{b}, \mathrm{c}}$, Keisuke Ono $^{\mathrm{d}}$, \\ Wonsik Kim ${ }^{\mathrm{d}}$, Masaharu Yokoi ${ }^{\mathrm{e}}$, Chun-Ta Lai ${ }^{\mathrm{f}}$ \\ ${ }^{a}$ Department of Natural Environmental Studies, University of Tokyo, Kashiwa, Chiba, \\ Japan \\ ${ }^{b}$ Atmosphere and ocean research institute, University of Tokyo, Kashiwa, Chiba, Japan \\ ${ }^{c}$ Institute of Industrial Science, University of Tokyo, Komaba, Tokyo, Japan \\ ${ }^{d}$ National Institute for Agro-Environmental Sciences, Tsukuba, Ibaraki, Japan \\ ${ }^{e}$ SANYO TRADING CO., LTD., Tokyo, Japan. \\ ${ }^{f}$ Department of Biology, San Diego State University, 5500, Campanile Drive, San Diego, \\ CA 92182, USA
}

\begin{abstract}
We observed stable isotopes in precipitation and atmospheric water vapor over a humid subtropical rice paddy field in Tsukuba, Japan, from June 2013 to May 2014. We used observed isotope ratios, in combination with an isotope-enabled general circulation model (GCM; Isotopes-incorporated Global Spectral Model: IsoGSM) to improve our understanding of the impacts of moisture sources and transport on the variability of water vapor isotopes. The isotopic measurements of water vapor and precipitation suggested that vapor isotopes in the study area were controlled by not only air-rain isotopic exchange, but also other kinetic effects associated with land evapotranspiration and large scale atmospheric circulation at the seasonal time scale. The contribution of land evapotranspiration to local water vapor content $\left(F_{E T}\right)$ was approximately $16.0 \pm 12.3 \%$ as an annual average, with a summer maximum of $20.5 \pm 12.9 \%$. Our results show that large-scale atmospheric circulation is the primary control on the variability
\end{abstract}

\footnotetext{
* Corresponding author

Email address: weizw@aori.u-tokyo.ac.jp (Wei Zhongwang)
}

Preprint submitted to Journal of Hydrology

October 29, 2015 
of near surface water vapor $\delta D$. An IsoGSM tagging simulation experiment demonstrated that the large temporal variation of surface water vapor isotopes can primarily be attributed to advection and mixing of moisture from different oceanic source regions.

Keywords: Water vapor isotope variability, d-excess, kinetic effects, water vapor source

\section{Introduction}

Measurements of water isotopic composition have been used in many studies to trace the origin and movement of atmospheric water (e.g., Craig, 1961 Dansgaard, 1964, Strong et al., 2007, Gat, 1996, Samuels-Crow et al., 2014a b

5 Lai and Ehleringer, 2011; Tremoy et al., 2012, 2014; Steen-Larsen et al., 2013, 2014b; Worden et al., 2007). Most of these studies have focused on condensed phases (i.e., precipitation), with fewer studies considering the vapor phase. Despite a wide range of applications, water isotopic composition in the condensed phase is too coarse to determine the dynamical and microphysical processes involved in atmospheric moisture evolution. Water vapor observation is not limited to rainy days, but can be done continuously over synoptic events and seasons (Angert et al. 2008). Water vapor isotopic composition is a useful tool to investigate land vegetation activity and to understand vegetation-atmosphere exchange processes (e.g., Good et al., 2014, Wei et al. 2015).

Recently, water vapor isotopic measurements were shown to be useful for constraining state variable simulations in general circulation models (GCMs) (e.g., Bonne et al., 2014 Steen-Larsen et al., 2014a). Yoshimura et al. (2014) conducted the first ideal observation system simulation experiment, through the combination of a local transform ensemble Kalman filter and an isotope-enabled 
data set of surface vapor isotope measurements, model simulations were significantly improved in both the vapor isotopic and meteorological fields. Satellitebased water vapor isotope measurements have been used for validating GCMs and partitioning the global hydrologic water flux (e.g., Frankenberg et al., 2009

${ }_{25}$ Good et al. 2015a b). However, their inherent uncertainties are likely too large to quantify sub-grid scale hydrological processes.

Previous studies have identified the factors that control the isotopic signatures of water vapor over oceans (e.g., Benetti et al., 2014, 2015, SteenLarsen et al. 2014b, 2015), ice sheets (Steen-Larsen et al., 2013), plateaus (e.g., 30 Galewsky and Samuels-Crow, 2014a b; Samuels-Crow et al. 2014a b), and land „surfaces under various climatic conditions (e.g., Welp et al., 2012, Berkelhammer et al., 2013; Tremoy et al., 2012, 2014, Lee et al., 2006, Noone et al., 2013. Wen et al., 2010, Huang and Wen, 2014: Laskar et al., 2014). Common findings of these studies are large variations in the atmospheric water vapor isotopic 35 composition over daily to seasonal time scales, irrespective of geographical conditions. Such variation is related to specific hydrological processes. For example, during precipitation events, water vapor isotopes are significantly affected by air-precipitation isotopic exchange (e.g., Huang and Wen, 2014, Lawrence et al. 2004, Wen et al., 2010; Tremoy et al., 2014). Thus, some studies have 40 suggested that it is possible to derive a monthly water vapor isotope ratio from the precipitation isotope ratio (e.g., Jacob and Sonntag, 1991; Lee et al., 2006. Wen et al., 2010). This approach is attractive because information regarding the precipitation isotope ratio (such as the Global Network of Isotopes in Precipitation [GNIP] dataset) is readily available (Lee et al., 2006). A number of studies 45 have concluded that local evapotranspiration $(E T)$ is a major contributor to the stable isotope composition of near surface water vapor in well-vegetated areas (e.g., Welp et al. 2008; Noone et al., 2013) or the sea surface (e.g., Benetti et al., 
2014).

Some studies have identified the importance of other factors, such as the

50 isotopes to diagnose moisture paths transported from three different oceans. They reported a low deuterium isotope ratio when moisture advection originated from the Gulf of Mexico (warmer than the Pacific Ocean) and a high ratio if moisture originated from the Pacific Ocean. By investigating the relaet al. (2006), Wen et al. (2010) and Huang and Wen (2014) suggested the dominant effect of Rayleigh distillation during large scale moisture transport.

The use of high frequency water vapor isotopes has a great potential to improve our understanding of the mechanisms that control stable isotope variability in hydrological processes. Despite these advances, there are several problems when using high frequency water vapor isotope measurements: 1) continuous measurements that cover multiple seasons are scarce (e.g., Farlin et al., 2013 , Noone et al., 2013); 2) very few study has yet been conducted at sites with changing vegetation cover over multiple seasons (Bastrikov et al. 2014); and 3) topic variability of water vapor observed at a single tower. Studies investigating the exact cause(s) of what controls long-term isotopic variability are rare.

In this study, we conducted a long-term water vapor isotopic study that uses in-situ isotopes and meteorological measurements along with an isotopeenabled GCM, to explore the impact of oceanic water sources on water vapor isotopic variability from daily to seasonal time scales over a rice paddy field in Tsukuba, Japan. We used isotopic information to partition water vapor content into contributions from local and remote-source components. Tagging experiments conducted using the Isotopes-incorporated Global Spectral Model 
(IsoGSM) were used to understand the role of large scale moisture transport in the observed isotopic variability.

\section{Materials and methods}

\subsection{Site description}

The study site $\left(36^{\circ} 03^{\prime} 14.3^{\prime \prime} \mathrm{N}, 140^{\circ} 01^{\prime} 36.9^{\prime \prime} \mathrm{E}\right.$, a.s.l. $\left.12 \mathrm{~m}\right)$ was located in a rectangular $100 \mathrm{~m} \times 50 \mathrm{~m}$ cultivated plot near the center of a 150 -ha rice paddy field in Tsukuba. The location of the measuring instrument provided a sufficient fetch of uniform land cover for flux and isotope measurements. Cultivation activity influenced the land cover in different seasons. The field was sparsely covered by weeds in spring (March-April), and by a canopy of rice seedlings from May until harvesting at the end of August. The field was flooded during the growing season and allowed to drain in the rest of the year. The maximum canopy height was about $1.1 \mathrm{~m}$ and the maximum leaf area index was $6.2 \pm 1.4$ in July 2014. The site has a warm and humid climate, with a mean annual air temperature of $13.5^{\circ} \mathrm{C}$ and mean annual precipitation of $1235 \mathrm{~mm}$ (Saito et al.

90 2005). The site has participated in AsiaFlux activities since 1999. Detailed information regarding meteorological and flux measurements can be found on the AsiaFlux website (http://asiaflux.net/index.php?page_id=83). Our study area is located near the western Pacific Ocean, which is under the influence of a tropical to subtropical climate, with a monsoon period in both summer and winter. In different seasons, this region potentially receives moisture from different oceans. Furthermore, our study was conducted in a large paddy field. Cultivation and irrigation activities influenced the surface cover; thus, we expected significant differences in the evapotranspiration isotopic pattern among seasons. 
We collected water vapor and precipitation samples. All isotope measurements are presented in parts per thousand using $\delta$ notation:

$$
\delta=\left(\frac{R_{\text {sample }}}{R_{\text {standard }}}-1\right) \times 1000
$$

where $R_{\text {sample }}$ and $R_{\text {standard }}$ are the ratios of oxygen mass 18 to mass 16 $\left({ }^{18} \mathrm{O} /{ }^{16} \mathrm{O}\right)$ or deuterium to hydrogen $(\mathrm{D} / \mathrm{H})$ of a sample (water vapor or precip(see supplementary Figure S1). The carry-over from the different previous samples were virtually removed. Our method reduced the number of injections per sample to four (compared to six in the manufacturer's recommended method) 
125 the results were averaged into 1-minute interval. A shielded air intake installed at a height of 2-m was connected to an A0311 module using a 14-m Teflon inlet tube. The flushing time was about $2 \mathrm{~min}$. We did not heat the tubing because the air temperature was higher than the dew point temperature ${ }_{145}$ (not shown). Two in-house water standards $\left(-0.3 \%\right.$ and $-26.0 \%$ for $\delta^{18} O$ and

where $n$ is the number of observations for each day, and $\delta_{p, i}$ and $P_{i}$ are the $\delta$ value and the total amount of the $i$ th precipitation, respectively. Assuming that water vapor and precipitation are in isotopic equilibrium, the isotopic composition of water vapor $\delta_{v, e}$ can be calculated from $\delta_{p}$ by incorporating a temperaturedependent equilibrium fractionation factor $\alpha_{e q}$ (Majoube, 1971):

$$
\delta_{v, e}=\left(\frac{1+\delta_{p} / 1000}{\alpha_{e q}}\right) \times 1000
$$

Water vapor isotopic measurements are briefly summarized here and a detailed description can be found in Wei et al. (2015). The measurement system consisted of a high frequency Picarro cavity ring-down spectrometer (L2120-i), standard delivery module (A0101), high precision vaporizer (A0211), and 16-port distribution manifold (A0311). Measurements were made every 2 seconds, and 
$-1.2 \%$ and $-197.9 \%$ for $\delta D$ ) were vaporized by the standard delivery module, mixed with dry room air and transferred to the analyzer. Each calibration cycle lasted $30 \mathrm{~min}$ for each standard. The results showed a high precision with std $\pm 0.3 \%$ for $\delta^{18} O$ and $\pm 1.3 \%$ for $\delta D$. The standard water was changed every 6 months. We also evaluated the concentration dependence of our instrument by injecting different amounts of standard water into the vaporizer. We did not correct the concentration dependence effect because the measurements generally worked well within the range of water vapor concentration encountered during our study period (Figure 1b). However, the large measurement uncertainty under low water vapor concentration suggested that the correction of the raw measurements using the humidity-isotope response functions (Steen-Larsen et al. 2014b) might be required. Unfortunately, there was a data gap from 22 October to 23 December 2013, due to a pump failure.

To identify the source of atmospheric moisture and its transport pattern, we briefly describe the theoretical framework for interpreting paired isotope ratios and specific humidity established by Noone (2012). The framework, composed of a set of simple processes, enables the use of isotopic data to identify the hydrological process under idealized atmospheric conditions. We used two processes in the framework: 1) Rayleigh distillation curves (case b in Noone (2012)), representing a pseudoadiabatic process based on oceanic temperatures, with an initial $\delta D$ value of $-80 \%$ (approximating the value of vapor in equilibrium with the ocean) in an open system, and 2) a mixing line, which represents a special case when the source water is the infinite reservoir of vapor in thermodynamic equilibrium (i.e., saturated) with the ocean surface (case e in (Noone, 2012)).

\subsection{IsoGSM simulation}

To investigate the impact of large-scale moisture transfer on the isotopic variability of near-surface water vapor, we used IsoGSM, a global spectral model 
that incorporates water isotope tracers (Yoshimura and Kanamitsu, 2009). IsoGSM „simulations have been validated by ground-based isotope observation (e.g., Far175 lin et al. 2013; Uemura et al. 2008) and satellite observation (e.g., Frankenberg et al. 2009). These studies showed that IsoGSM is capable of reproducing the daily averaged variability in $\delta D$ of near-surface water vapor associated with synoptic weather cycles. The model in this study had a horizontal scale of about $200 \mathrm{~km}$ (T62) and 28 vertical levels (L28), with six-hour intervals. IsoGSM uses the spectral nudging technique (Yoshimura et al., 2008) to include the actual atmospheric thermodynamic situation. The default land surface scheme in IsoGSM is the Noah model (Ek et al., 2003). In IsoGSM, isotopic fractionation takes place whenever phase transition occurs. Most isotopic fractionation is assumed to occur at thermodynamic equilibrium, except for three particular cases: surface evaporation from open water, condensation from vapor to ice in supersaturation conditions under $-20^{\circ} \mathrm{C}$, and evaporation and isotopic exchange from liquid raindrop to unsaturated air. IsoGSM assumes a constant isotopic value $(0 \%)$ for the ocean water and no fractionation when water evapotranspires over land surface (i.e., $100 \%$ transpiration is assumed). The isotopic ratio of land surface storage (one snow layer and four soil layers) is calculated based on the isotopic mass balance equations, assuming evapotranspiration and surface runoff occur only from the first layer of the soil and that base runoff occurs from the deepest (fourth) layer of the soil without fractionation. Readers are directed to Yoshimura et al. (2008), Yoshimura et al. (2014) and He et al. (2014) for a detailed description of the model setup. Over a long time period (such as monthly time scale), the planetary boundary layer can be effectively treated as a 1-box model, with input (evapotranspiration) and output (air from the free atmosphere) only from the top and bottom. Near surface horizontal advection can be assumed to be small and is smoothed out by the temporal averaging (Helliker 
turning off all the other isotopic fractionation in the atmosphere. For each of these simulation, the evaporated water is marked by its origin with a tag. Once this tagged vapor is added to the atmosphere, it undergoes exactly the same processes as normal vapor (It is allowed to advect, mix, condense and rainout in 
the atmoshphere. Therefore, it has influence neither on the hydrological cycle nor on isotopic processes.), except it is not factored into energy budget calculations. The method used here allows a direct quantification of the amount of water advected from tagging region. Similar experiments were conducted to understand the cause of the seasonal variation in the oxygen isotopic composition of precipitation along the western U.S. coast (Buenning et al. 2012). In our study, vapor was tagged within a $10^{\circ} \times 10^{\circ}$ boxed sub-region (see Sec.3.4). The atmospheric column precipitable water derived from tagged boxes was used to identify the source region of the water vapor.

\section{Results and discussion}

3.1. Characteristics of observation and simulation

Figure 2 shows the daily precipitation $(P)$, daily averaged water mixture ratio $(Q), \delta^{18} O, \delta D$ and $d$-excess of water vapor (with subscript $v$ ), and the weighted precipitation amount of $\delta^{18} O, \delta D$ and $d$-excess (with subscript $p$ ). $Q$ varied from 3000 to 35000 ppmv. $\delta^{18} O_{v}$ fluctuated from $-28.4 \%$ to $-11.0 \%$, $\delta D_{v}$ fluctuated from $-206.8 \%$ to $-78.6 \%$, and $d_{v}$-excess fluctuated from $-1.8 \%$ to $31.9 \%$. There was considerably less day-to-day variation in $\delta^{18} O_{v}, \delta D_{v}$, and $d_{v}$ - excess in the warm season than the cold season. Similar results were observed in Beijing $\left(40^{\circ} 00^{\prime} \mathrm{N}, 116^{\circ} 23^{\prime} \mathrm{E}\right.$ (Lee et al. 2006)). The seasonal variation can be explained by strong summer monsoon activity in East Asia, including Japan and southeastern China (Wen et al., 2010, Laskar et al., 2014). The observed $\delta_{p}$ varied widely, ranging from $-15.7 \%$ to $2.9 \%$ for $\delta^{18} O_{p}$, from $-114.9 \%$ to $34.5 \%$ for $\delta D_{p}$, and from $-21.6 \%$ to $27.7 \%$ for $d_{p}$-excess. Positive $\delta^{18} O_{p}$ and $\delta D_{p}$ values tended to occur in small showers, which were subject to sub-cloud evaporation (Wen et al., 2010, Huang and Wen, 2014). Water vapor appeared to be isotopically in equilibrium with surrounding raindrops during 
a precipitation event. Because the water vapor mixing ratio increased with precipitation, the vapor isotope ratios became progressively lower during rainy periods. $\delta^{18} O_{v}$ and $\delta D_{v}$ were consistently lower than but varied together with precipitation isotopes. Similarly, $d_{v}-$ excess consistently varied with $d_{p}$-excess. As noted in previous studies (e.g., Lee et al., 2006; Welp et al., 2008, Wen et al. 2010), near surface vapor isotope ratios approached the equilibrium state with the ratios in precipitation. These interactions between raindrops and the surrounding water vapor during precipitation events have been quantitatively estimated by Lee and Fung (2008).

Monthly isotope and weather variables are shown in Figure 3. Seasonal changes of relative humidity $R H$, air temperature $T_{a}$, and $\delta D$ and $d$-excess are plotted in Figure $3 R$ and $T_{a}$ displayed a clear seasonal signal. There was no clear seasonal cycle in $\delta_{v}$ or $\delta_{p}$, although slightly lower values were apparent in winter. In contrast, $d_{v}$-excess and $Q$ displayed a clear seasonal cycle, which was different from that observed in those areas influenced by the typical arid continental climate at similar latitudes (e.g., Zhangye, China $\left(38^{\circ} 51^{\prime} \mathrm{N}, 100^{\circ}\right.$ 22 ' E) (Huang and Wen, 2014)). The highest and lowest monthly mean values of $d_{v}$ - excess were found in January (27.3\%o) and July (11.4\%o), respectively. $d_{p}-$ excess was more variable with the highest value found in January $(16.3 \%$ o and the lowest in November (1.5\%).

Figure 2 compares an IsoGSM isotopic simulation at $2 \mathrm{~m}$ with surface observations. IsoGSM reproduced the variability of $Q$ very well $\left(\mathrm{r}^{2}=0.95\right.$, RMSE $=832 \mathrm{ppmv})$. This implies that our site can reasonably capture $\delta_{v}$ variation under the influence of regional-scale advection of atmospheric moisture $\left(\mathrm{r}^{2}=\right.$ $0.64, \mathrm{RMSE}=10.8 \%$ for $\delta D_{v}, \mathrm{r}^{2}=0.70, \mathrm{RMSE}=1.2 \%$ for $\left.\delta^{18} O_{v}\right)$. Variability in $d$-excess was difficult to simulate (e.g., Bonne et al., 2014, Steen-Larsen et al. 2014a). IsoGSM predicted a relatively constant $d_{v}$-excess value of $10 \%$ 
and generally underestimated observed $d_{v}$-excess values throughout the observation period $\left(\mathrm{r}^{2}=0.20, \mathrm{RMSE}=5.5 \%\right.$ ). Model discrepancies indicated that water vapor isotopes were an additional constraint that highlighted the misrepresentation of hydrological processes in the simulation. We did not further explore the possible causes of model bias. Rather, we focused on identifying the controls of near surface $\delta_{v}$. Despite the discrepancy in modeled isotopic variability, IsoGSM provided important information regarding how large-scale moisture transfer influenced the isotopic variation of surface water vapor. The strong fit at our site suggested that the variability in near-surface water vapor is primarily influenced by large-scale advection, whereas local evapotranspiration likely played an insignificant role (because IsoGSM reproduces large-scale advection rather than local evapotranspiration). However, more evidence is required to determine the driving forces behind the variability of $\delta D_{v}$. Hereafter, we only present results based on $\delta D$ and $d$-excess. Similar results obtained from $\delta^{18} \mathrm{O}$ are not shown here.

\subsection{Effect of precipitation on the isotopic variability of water vapor}

The observed and simulated isotopic ratios (Figure 2 indicated that during non-rainy days, there was no significant isotopic variation of water vapor. On rainy days, the isotopic composition of water vapor changed suddenly and considerably in relation to the isotopic composition of rain (Figure 2). For example, in association with a precipitation event that occurred on October 15 (19 mm), $Q$ increased from 14520 ppmv to $18180 \mathrm{ppm}$, whereas $\delta^{18} O_{v}$ decreased from $-99.2 \%$ to $-180 \%$. This variation indicated a significant isotopic impact of raindrops on near surface water vapor. To verify this quantitatively, we calculated $\delta D_{v, e}$ based on Equation (3) and compared it with $\delta D_{v}$ in Figure 4 $\delta D_{v}$ agreed reasonably well with $\delta D_{v, e}(\mathrm{r}=0.74)$ at the daily time scale. This robust relationship indicated that atmospheric vapor approached an isotopic 

our equilibrium predictions differed greatly from the monthly $\delta D_{v}$ (Figure 3 $\mathrm{r}=0.22$ ). These results contradicted previous findings, which demonstrated a reasonable agreement between $\delta D_{v}$ and $\delta D_{v, e}$ on a monthly time scale Jacob and Sonntag, 1991; Lee et al., 2006, Wen et al., 2010; Huang and Wen, 2014). and predicted equilibrium values. Predicted $d_{v, e}-$ excess was generally simila to that of precipitation. A possible reason for this is that condensation affected $\delta$ without changing $d$-excess (Dansgaard, 1964, Bonne et al., 2015).

\subsection{Effect of local evapotranspiration on the isotopic variability of water vapor}

During non-rainy days, surface ET can significantly contribute to the temporal variation in $\delta_{v}$. We investigated this effect using Equation (5) with three parameters, $\delta_{E T}, \delta D_{v}$ and $\delta_{b g}$ (the isotopic ratio of the background air). Hourly $\delta_{E T}$ values were estimated by the Keeling plot approach (Keeling, 1958), whenever data points were available $(\mathrm{N}>40)$ in a given hour and with a high coefficient of determination $\left(\mathrm{r}^{2}>0.8\right)$ from each linear regression. Wei et al. [2015] demonstrated that at this site, the assumptions underlying the Keeling plot were rarely met and the uncertainty was quite large, especially under nighttime or weakly turbulent conditions. We assumed no evapotranspiration at night (19:00 p.m. 7:00 a.m.) and used daily average $\delta_{E T}$ values (sensible heat weighted). $\delta D_{v}$ at simulated CBL height $\left(\delta_{b g}\right)$ was derived from linear interpolation of water vapor isotopic ratio from $925 \mathrm{hpa}$ (about 750m), $850 \mathrm{hpa}$ (about $1500 \mathrm{~m}$ ) and 700 hpa level (about $3000 \mathrm{~m}$ ) for three reasons: 1)IsoGSM simulated the convective boundary layer extended with a height of 0.8 to $2 \mathrm{~km}$ during our observation periods (see supplementary Figure S2); 2) IsoGSM is nudged by United States National Centers for Environmental Prediction (NCEP) reanalysis data, and thus reproduces the day-to-day variability induced by large-scale convection; 
and 3) the model produces a satisfactory qualitative agreement for the isotopic composition of atmospheric moisture at 2-m level (Figure 2).

The variability of $\delta_{E T}, \delta_{b g}$, and $\delta D_{v}$ at the daily time scale is shown in 335 Figure 5. $\delta_{E T}$ ranged from $-112.2 \%$ to $37.1 \%$. A significant difference in $\delta_{E T}$ was found between the growing and non-growing seasons. In the summer season (June-July-August, JJA), $\delta_{E T}$ generally depended on transpiration. $\delta_{E T}$ was closely coupled with irrigation water, indicating small isotopic fractionations during this period (Wei et al. 2015). In the non-growing season, $\delta_{E T}$ was con340 siderably more variable than in JJA. Without irrigation and consequently with negligible transpiration, $\delta_{E T}$ was controlled by other meteorological parameters, such as precipitation and radiation. For example, a rapid decrease of $\delta_{E T}$ corresponded to evaporation after precipitation on 18 October (from $-51.8 \%$ on 18 October to $-97.81 \%$ on 20 October). Then $\delta_{E T}$ values gradually increased 345 due to soil evaporation (-69.2\% on 21 October). Compared to $\delta_{E T}, \delta D_{v}$ and $\delta_{b g}$ clearly displayed seasonal variation and were highly correlated with each other. These results suggest that $\delta D_{v}$ was mainly controlled by the air from the free atmosphere. The largest difference between $\delta D_{v}$ and $\delta_{b g}$ was found in JJA, whereas the smallest difference was found in winter (December-January350 February, DJF). In JJA, relatively high $\delta D_{v}$ values were likely due to enrichment by transpiration, whereas a low $d_{v}$-excess is a result of the negligible kinetic effect associated with transpiration by short vegetation (Lai et al., 2008). Our results showed a large $E T$ impact during the peak of the rice growing season in JJA. The monthly averaged $\delta D_{v}, \delta_{E T}$ and $\delta_{b g}$ used to estimate monthly $F_{E T}$ 355 are listed in Table 2. On average, $F_{E T}$ was estimated as $16.0 \pm 12.3 \%$, with the highest value in JJA $(20.5 \pm 12.9 \%)$ and lowest in DJF $(7.1 \pm 13.2 \%)$. These estimates are consistent with simulated seasonal averaged latent heat fluxes (Figure 6. Thus, we suggest that the primary control on the variability of near surface 
$\delta_{v}$ and humidity during non-rainy days is atmospheric circulation, with local

360

ET playing a secondary role, especially in DJF.

Nevertheless, large uncertainties were still present in these estimates. The ability of IsoGSM to reproduce water vapor and its isotopic variability observed at a single location was unexpected because the IsoGSM simulation was performed at a coarse resolution $(200 \mathrm{~km} \times 200 \mathrm{~km})$, which is far greater than the footprint of ground-based measurements (Farlin et al. 2013$)$. Furthermore, feedback from the local land contribution was not carefully addressed. IsoGSM neglects possible fractionation during transpiration, which is a common problem in most isotope-enabled GCMs. Bias also arises from neglecting horizontal advection, which is likely to alter the near surface $\delta D_{v}$. Very few measurements of $\delta_{b g}$ are currently available (Tsujimura et al., 2007). Here, we used isotopic ratio of water vapor linear interpolated from water vapor isotopic ratio at different levels as background. However, IsoGSM simulated CBL height is rough, and the vertical profile of water vapor isotopes is general non-linear. To reduce the uncertainty in evaluating $F_{E T}$, a further study based on measured middle and low troposphere isotopes of water vapor isotopes (such as satellite measurement) should be conducted. Nevertheless, our results suggested that near surface water vapor isotope ratio is not significantly affected by ET. As explained previously, the high correlation between measured $\delta D_{v}$ at 2-m and simulated $\delta_{b g}$ at CBL height $(\mathrm{r}=0.74)$ with the insignificant correlation between measured $\delta D_{v}$ at 2-m and Keeling plot estimated $\delta_{E T}(\mathrm{r}=0.18)$ also suggested the dominant role of air from the free atmosphere.

\subsection{Remote controls on the isotopic variability of water vapor}

To understand the remote controls on water vapor isotopic variation, we conducted a water tagging experiment to identify the origin of the water vapor. 
in JJA (Figure 7). There was a significant contribution from the surrounding ocean (both the Japan Sea and Pacific Ocean; Areas c, d, e, and f). Assuming all water vapor originated from the tagged boxes, we were able to calculate the fractional relative contribution for each box. As Figure 8 shows, Area e had the most significant impact on moisture sources in JJA, corresponding to about $32 \%$ of the total contribution. In SON, flow from either the Japan Sea (Area d, $24 \%$ ) or the high-latitude Pacific Ocean (Area f, 34\%) had the dominant role in controlling the observed isotopic variability at our site. Water vapor generally originated from the Japan Sea in DJF (Area d, 40\%). Likewise, variable sources of water vapor were found in MAM (March-April-May), with the largest contribution from Area d (29\%). We documented the $850 \mathrm{hpa}$ isotope ratios based on the wind direction $\left(0^{\circ}\right.$ to $90^{\circ}$, Area f; $90^{\circ}$ to $180^{\circ}$, Area e; $180^{\circ}$ to $270^{\circ}$, Area $\mathrm{a}+\mathrm{c} ; 270^{\circ}$ to $360^{\circ}$, Area $\left.\mathrm{b}+\mathrm{d}\right)$. The results showed that the original source had a significant impact on water vapor isotopes (Figure 9p. Seasonal and regional differences of $\delta D_{v}$ at the $850 \mathrm{hpa}$ level were related to $R H$ relative sea surface temperature $(\mathrm{SST})\left(R H_{s}\right)$ differences (not shown). More water vapor evaporated from areas with a low $R H_{s}$ and a higher isotopic composition than from relatively high $R H_{s}$ water bodies region. Through vertical mixing, surface water vapor isotopes can be significantly affected by different oceanic sources. Based on the tagging experiments, the observed seasonal cycle of $d_{v}$-excess (Table 1) can also be explained by the seasonal change in the primary marine moisture sources. As shown in Figure 2, the highest $d_{v}-$ excess occurred in winter, while the lowest occurred in summer. Because moisture was generated under conditions with a high relative humidity in summer (not shown), evaporated water tended to have a lower $d_{v}$-excess. On the other hand, the high $d_{v}$-excess resulting from strong kinetic effects corresponded to low relative humidity and strong evaporation (Figure 6) above the ocean in DJF. These results were con- 
sistent with the negative correlation between $d_{v}$-excess and relative humidity observed above the ocean (Dansgaard, 1964, Uemura et al. 2008, Benetti et al. 4152014 2015.

The IsoGSM simulation suggested that the mixing of air from multiple sources was likely a major factor controlling the water vapor isotopic variation at our study site on non-rainy days. To further explore the mechanisms responsible for the observed isotopic variation and to validate the simulation results, we plotted daily mean $\delta D_{v}$ as a function of specific humidity $q$ for each season. As shown in Figure 10, the moistening process (increasing $q$ ) acted to enrich water vapor isotope ratios. During the winter season (DJF), $q$ generally varied from 2 to $10 \mathrm{~g} / \mathrm{kg}$. $\delta D_{v}$ was clustered tightly around the mixing line, suggesting a mixing of marine moist air and a dry air mass. This supports the idea that in general, cold northerly winds transport water vapor that originates from the Japan Sea to our site (Figure 8). Outside of the winter season, $q$ varied over a wide range $(2<\mathrm{q}<25 \mathrm{~g} / \mathrm{kg})$, while $\delta D_{v}$ fell in the range between the Rayleigh curve and the mixing line. ET might be one of the factors pulling data points away from the evaporation line. However, most data points were more depleted than $-80 \%$, suggesting a negligible impact of $E T$ on $\delta D_{v}$ variation (most of the time, $E T$ tends to increase $\delta D_{v}$ (Risi et al. 2010) $)$. Local moisture at our site was likely a result of combined marine sources in these seasons. The large variability of $q$ and $\delta D_{v}$ was related to the mixing of different oceanic sources (Figure 8) of distinct isotopic ratios (Figure 9). Mixing can occur between any number of air masses that deviate from a single curve. Hence, the entire area between the Rayleigh curve and the mixing line can be considered a result of mixing (Galewsky and Samuels-Crow, 2014a). The tagging experiment and $q$ $\delta D_{v}$ framework provide consistent evidence that the mixing of multiple moisture sources plays an important role in controlling $\delta D_{v}$ variability in this region. In 

2008, Wen et al., 2010, Huang and Wen, 2014), our measurements showed that $q$ was a poor predictor of $\delta D_{v}$ because of the mixing processes. These results suggest that the common assumption in a Rayleigh distillation model that water vapor originates from a single source, is unable to reproduce the water vapor isotopic variability over a subtropical area. The isotopic variability of water vapor also depends on its air trajectory. In DJF, a lot of vapor is supplied from the Japan Sea, which creates large amounts of snow along the coast of the Japan Sea, resulting in isotopic depleted water vapor and a high d-excess. By contrast, in JJA, water vapor was derived from several adjacent oceans, with high humidity and a low evaporation rate, which resulted in an enriched isotopic signature and low $d_{v}$-excess. Being different from those inland area, water vapor source area is very close to our site, the removal of heavy isotopes from water vapor by Rayleigh distillation processes (moisture recycling) is insignificant. On the other hand, large differences of $\delta D_{v}$ at 850 hpa level from different areas were clearly observed in each season (see supplementary Figure S3). Thus, we believe source origin of water vapor, rather than physical processes along an air mass moving trajectory, is the primary control of water vapor isotopic variation. We also noted that some of the $\delta D_{v}$ values in the wet season were more depleted than those predicted by Rayleigh distillation. These data can be explained by shallow dry convection. Strong shallow dry convective activity generates water vapor $\delta D_{v}$ below the Rayleigh curve, in a process known as the isotope amount effect (Bony et al. 2008, Galewsky and Samuels-Crow, 2014a b). However, more evidence is required to confirm this. 


\section{Conclusions}

We collected long-term observations of stable isotopes for oxygen and hydrogen in precipitation and water vapor from June 2013 June to May 2014 in Tsukuba, Japan. We also investigated the isotopes of precipitation, water vapor, evapotranspiration, and large-scale moisture derived by IsoGSM to understand the variability of water isotopologues in near-surface atmospheric moisture. We conducted water tagging experiments, together with the observed $d_{v}$-excess and $q-\delta D_{v}$ framework, to discuss how remote controls could affect the isotopic variability of water vapor. The following conclusions were drawn:

(1) $d_{v}$ - excess and $Q$ displayed clear seasonal cycles, while the seasonal variations of $\delta D_{v}$ and $\delta^{18} O_{v}$ were insignificant.

(2) We successfully combined the GCM simulation (IsoGSM) with high-frequency water vapor isotopic measurements to disentangle the water vapor source and its hydrological processes. The model successfully replicated observed isotopic variability, suggesting its ability to reproduce moisture transport.

(3) The isotopic measurements of near surface water vapor and precipitation suggested that water vapor appeared to be isotopically in equilibrium with surrounding raindrops during a precipitation event. However, the equilibrium predictions from monthly $\delta D_{v}$ were heavily biased.

(4) The contribution of land evapotranspiration to local water vapor content $\left(F_{E T}\right)$ was approximately $16.0 \pm 12.3 \%$ on average. This revealed a significant seasonal cycle, where $F_{E T}$ was highest in JJA $(20.5 \pm 12.9 \%)$ due to the increased transpiration and lowest in DJF $(7.1 \pm 13.2 \%)$. Our results indicate that the primary control on near surface water vapor $\delta D$ variability is atmospheric circulation, with local evapotranspiration playing a secondary role. 
(5) The tagging experiments together with the $d_{v}$-excess and $q-\delta D_{v}$ framework provided consistent evidence that the large temporal variation of $\delta D_{v}$ could primarily be attributed to the advection of moisture from different source regions.

\section{Acknowledgments}

We are grateful to the reviewers for their comments to improve the quality of our manuscript. This study is supported by the Japan Society for the Promotion of Science (JSPS) Grants 23686071 and 23226012, SOUSEI Program and RECCA/SALSA project of MEXT, Project from MOE (Japanese Ministry of Environment) and CREST from Japan Science and Technology Agency. C.-T

Lai was supported by the U.S. National Science Foundation, Division of Atmospheric and Geospace Sciences under Grant Number AGS-0956425. All the data used in this study is available on request from the corresponding author (weizw@aori.u-tokyo.ac.jp).

\section{Reference}

Angert, A., Lee, J.E., Yakir, d., 2008. Seasonal variations in the isotopic composition of near-surface water vapour in the eastern Mediterranean. Tellus B 60, 674-684. doi $10.1111 / \mathrm{j} .1600-0889.2008 .00357 . \mathrm{x}$

Bastrikov, V., Steen-Larsen, H.C., Masson-Delmotte, V., Gribanov, K., Cattani, O., Jouzel, J., Zakharov, V., 2014. Continuous measurements of atmospheric water vapour isotopes in western Siberia (Kourovka). Atmospheric Measurement Techniques 7, 1763-1776. doi 10.5194/amt-7-1763-2014.

Benetti, M., Aloisi, G., Reverdin, G., Risi, C., Sèze, G., 2015. Importance of boundary layer mixing for the isotopic composition of surface vapor over the 
subtropical North Atlantic Ocean. Journal of Geophysical Research: Atmospheres 120, 2190-2209. doi:10.1002/2014JD021947.

Benetti, M., Reverdin, G., Pierre, C., Merlivat, L., Risi, C., Steen-Larsen, H.C., Vimeux, F., 2014. Deuterium excess in marine water vapor: Dependency on relative humidity and surface wind speed during evaporation. Journal of Geophysical Research: Atmospheres 119, 584-593. doi 10.1002/2013JD020535.

Berkelhammer, M., Hu, J., Bailey, A., Noone, D.C., Still, C.J., Barnard, H., Gochis, D., Hsiao, G.S., Rahn, T., Turnipseed, A., 2013. The nocturnal water cycle in an open-canopy forest. Journal of Geophysical Research: Atmospheres 118, 10,225-10,242. doi:10.1002/jgrd.50701.

Bershaw, J., Penny, S.M., Garzione, C.N., 2012. Stable isotopes of modern water across the Himalaya and eastern Tibetan plateau: Implications for estimates of paleoelevation and paleoclimate. Journal of Geophysical Research: Atmospheres 117. doi:10.1029/2011JD016132.

Bonne, J.L., Masson-Delmotte, V., Cattani, O., Delmotte, M., Risi, C., Sodemann, H., Steen-Larsen, H., 2014. The isotopic composition of water vapour and precipitation in Ivittuut, southern Greenland. Atmospheric Chemistry and Physics 14, 4419-4439. doi:10.5194/acpd-13-30521-2013.

Bonne, J.L., Steen-Larsen, H.C., Risi, C., Werner, M., Sodemann, H., Lacour, J.L., Fettweis, X., Cesana, G., Delmotte, M., Cattani, O., Vallelonga, P., Kjr, H.A., Clerbaux, C., Sveinbjrnsdttir, .E., Masson-Delmotte, V., 2015. The summer 2012 greenland heat wave: In situ and remote sensing observations of water vapor isotopic composition during an atmospheric river event. Journal of Geophysical Research: Atmospheres 120, 2970-2989. doi:10.1002/2014JD022602. 
Bony, S., Risi, C., Vimeux, F., 2008. Influence of convective processes on the isotopic composition $(\delta 18 \mathrm{O}$ and $\delta \mathrm{D})$ of precipitation and water vapor in the tropics: 1. Radiative-convective equilibrium and Tropical OceanGlobal Atmosphere-Ccoupled ocean-atmosphere response experiment (togacoare) simulations. Journal of Geophysical Research: Atmospheres 113. doi:10.1029/2008JD009942.

Buenning, N.H., Stott, L., Yoshimura, K., Berkelhammer, M., 2012. The cause of the seasonal variation in the oxygen isotopic composition of precipitation along the western u.s. coast. Journal of Geophysical Research: Atmospheres 117. doi $10.1029 / 2012 J D 018050$

Craig, H., 1961. Isotopic variations in Meteoric Waters. Science 133, 1702-1703. doi $10.1126 /$ science.133.3465.1702

Dansgaard, W., 1964. Stable isotopes in precipitation. Tellus 16, 436-468. doi $10.1111 / \mathrm{j} .2153-3490.1964 . t b 00181 . x$.

Ek, M.B., Mitchell, K.E., Lin, Y., Rogers, E., Grunmann, P., Koren, V., Gayno, G., Tarpley, J.D., 2003. Implementation of Noah land surface model advances in the National Centers for Environmental Prediction operational mesoscale घ Eta model. Journal of Geophysical Research: Atmospheres 108. doi 10.1029/ 2002JD003296.

Farlin, J., Lai, C.T., Yoshimura, K., 2013. Influence of synoptic weather events on the isotopic composition of atmospheric moisture in a coastal city of the 1002/wrcr.20305

Frankenberg, C., Yoshimura, K., Warneke, T., Aben, I., Butz, A., Deutscher, N., Griffith, D., Hase, F., Notholt, J., Schneider, M., Schrijver, H., Röckmann, 
T., 2009. Dynamic processes governing lower-tropospheric HDO/H2O ratios 565 as observed from space and ground. Science 325, 1374-1377. doi 10.1126/ science.1173791.

Galewsky, J., Samuels-Crow, K., 2014a. Summertime moisture transport to the southern south American Altiplano: Constraints from in situ measurements of

口 water vapor isotopic composition. Journal of Climate 28, 2635-2649. doi 10. 1175/JCLI-D-14-00511.1.

Galewsky, J., Samuels-Crow, K., 2014b. Water vapor isotopic composition of a stratospheric air intrusion: Measurements from the Chajnantor Plateau, 口 Chile. Journal of Geophysical Research: Atmospheres 119, 9679-9691. doi 10. 1002/2014JD022047.

575 Gat, J.R., 1996. Oxygen and hydrogen isotopes in the hydrologic cycle. Annual a Review of Earth and Planetary Sciences 24, 225-262. doi 10.1146/annurev. earth.24.1.225

van Geldern, R., Barth, J.A., 2012. Optimization of instrument setup and postrun corrections for oxygen and hydrogen stable isotope measurements of water by isotope ratio infrared spectroscopy (iris). Limnology and Oceanography: Methods 10, 1024-1036. doi:10.4319/lom.2012.10.1024.

Good, S.P., Noone, D., Bowen, G., 2015a. Hydrologic connectivity constrains ๓ partitioning of global terrestrial water fluxes. Science 349, 175-177. doi:10. 1126/science.aaa5931.

Good, S.P., Noone, D., Kurita, N., Benetti, M., Bowen, G.J., 2015b. D/h isotope ratios in the global hydrologic cycle. Geophysical Research Letters 42, 5042-5050. doi:10.1002/2015GL064117.

Good, S.P., Soderberg, K., Guan, K., King, E.G., Scanlon, T.M., Caylor, K.K., 
2014. $\delta 2 \mathrm{H}$ isotopic flux partitioning of evapotranspiration over a grass field following a water pulse and subsequent dry down. Water Resources Research 50, 1410-1432. doi $10.1002 / 2013$ WR014333.

He, X., Kim, H., Kirstetter, P.E., Yoshimura, K., Chang, E.C., Ferguson, C.R., Erlingis, J.M., Hong, Y., Oki, T., 2014. The diurnal cycle of precipitation in regional spectral model simulations over west africa: Sensitivities to resolution and cumulus schemes. Weather and Forecasting 30, 424-445. doi 10.1175/ WAF-D-14-00013.1.

Helliker, B.R., Berry, J.A., Betts, A.K., Bakwin, P.S., Davis, K.J., Denning, A.S., Ehleringer, J.R., Miller, J.B., Butler, M.P., Ricciuto, D.M., 2004. Estimates of net co2 flux by application of equilibrium boundary layer concepts to co2 and water vapor measurements from a tall tower. Journal of Geophysical Research: Atmospheres 109. doi 10.1029/2004JD004532.

Huang, L., Wen, X., 2014. Temporal variations of atmospheric water vapor $\delta \mathrm{D}$ and $\delta 18 \mathrm{O}$ above an arid artificial oasis cropland in the Heihe River Basin.

口 Journal of Geophysical Research: Atmospheres 119, 11,456-11,476. doi 10. 1002/2014JD021891.

Jacob, H., Sonntag, C., 1991. An 8-year record of the seasonal variation of $2 \mathrm{H}$ and $18 \mathrm{O}$ in atmospheric water vapour and precipitation at Heidelberg, Germany. Tellus B 43.

Keeling, C.D., 1958. The concentration and isotopic abundances of atmospheric carbon dioxide in rural areas. Geochim. Cosmochim. Acta 13, 322-334. doi $10.1016 / 0016-7037(58) 90033-4$.

Lai, C.T., Ehleringer, J.R., 2011. Deuterium excess reveals diurnal sources 口 of water vapor in forest air. Oecologia 165, 213-223. doi 10.1007/ s00442-010-1721-2. 
Lai, C.T., Ometto, J.P., Berry, J.A., Martinelli, L.A., Domingues, T.F., Ehleringer, J.R., 2008. Life form-specific variations in leaf water oxygen口 18 enrichment in Amazonian vegetation. Oecologia 157, 197-210. doi 10. 1007/s00442-008-1071-5

Laskar, A.H., Huang, J.C., Hsu, S.C., Bhattacharya, S.K., Wang, C.H., Liang, M.C., 2014. Stable isotopic composition of near surface atmospheric water vapor and rain-vapor interaction in Taipei, Taiwan. Journal of Hydrology 519, 2091-2100. doi $10.1016 / j \cdot j h y d r o l .2014 .10 .017$.

Lawrence, J.R., Gedzelman, S.D., Dexheimer, D., Cho, H.K., Carrie, G.D., Gasparini, R., Anderson, C.R., Bowman, K.P., Biggerstaff, M.I., 2004. Stable 625 isotopic composition of water vapor in the tropics. Journal of Geophysical Research: Atmospheres 109. doi:10.1029/2003JD004046.

Lee, J.E., Fung, I., 2008. Amount effect of water isotopes and quantitative analysis of post-condensation processes. Hydrological Processes 22, 1-8. doi $10.1002 /$ hyp. 6637

Lee, X., Smith, R., WIilliams, J., 2006. Water vapour 18O/16O isotope ratio q in surface air in New England, USA. Tellus B 58, 293-304. doi $10.1111 / j$. 1600-0889.2006.00191.x.

Majoube, M., 1971. Fractionnement en oxygene-18 et en deuterium entre lfeau et sa vapeur. J. Chim. phys. 68, 1423-1436.

${ }_{635}$ Noone, D., 2012. Pairing measurements of the water vapor isotope ratio with humidity to deduce atmospheric moistening and dehydration in the

n tropical midtroposphere. Journal of Climate 25, 4476-4494. doi 10.1175/ JCLI-D-11-00582.1.

Noone, D., Risi, C., Bailey, A., Berkelhammer, M., Brown, D.P., Buenning, N., 
Gregory, S., Nusbaumer, J., Schneider, D., Sykes, J., Vanderwende, B., Wong, J., Meillier, Y., Wolfe, D., 2013. Determining water sources in the boundary layer from tall tower profiles of water vapor and surface water isotope ratios after a snowstorm in Colorado. Atmospheric Chemistry and Physics 13, 16071623. doi $10.5194 / \mathrm{acp}-13-1607-2013$. stable isotopes. Oecologia 127, 171-179.

Risi, C., Bony, S., Vimeux, F., Frankenberg, C., Noone, D., Worden, J., 2010. Understanding the Sahelian water budget through the isotopic composition of water vapor and precipitation. Journal of Geophysical Research: Atmospheres 115. doi $10.1029 / 2010$ JD014690

Saito, M., Miyata, A., Nagai, H., Yamada, T., 2005. Seasonal variation of carbon dioxide exchange in rice paddy field in japan. Agricultural and Forest Meteorology 135, 93 - 109. doi 10.1016/j.agrformet.2005.10.007

Samuels-Crow, K.E., Galewsky, J., Hardy, D.R., Sharp, Z.D., Worden, J., Braun, C., 2014a. Upwind convective influences on the isotopic composition of atmospheric water vapor over the tropical Andes. Journal of Geophysical Research: Atmospheres 119, 7051-7063. doi 10.1002/2014JD021487.

Samuels-Crow, K.E., Galewsky, J., Sharp, Z.D., Dennis, K.J., 2014b. Deuterium excess in subtropical free troposphere water vapor: Continuous measurements from the Chajnantor plateau, northern Chile. Geophysical Research Letters 41, 8652-8659. doi 10.1002/2014GL062302.

Steen-Larsen, H., Masson-Delmotte, V., Hirabayashi, M., Winkler, R., Satow, K., Prié, F., Bayou, N., Brun, E., Cuffey, K., Dahl-Jensen, D., Dumont, M., Guillevic, M., Kipfstuhl, S., Landais, A., Popp, T., Risi, C., Steffen, 
K., Stenni, B., Sveinbjörnsdottír, A., 2014a. What controls the isotopic composition of Greenland surface snow? Climate of the Past 10, 377-392. doi $10.5194 / \mathrm{cp}-10-377-2014$.

Steen-Larsen, H.C., Johnsen, S.J., Masson-Delmotte, V., Stenni, B., Risi, C., Sodemann, H., Balslev-Clausen, D., Blunier, T., Dahl-Jensen, D., Ellehøj, M.D., Falourd, S., Grindsted, A., Gkinis, V., Jouzel, J., Popp, T., Sheldon, S., Simonsen, S.B., Sjolte, J., Steffensen, J.P., Sperlich, P., Sveinbjörnsdóttir, A.E., Vinther, B.M., White, J.W.C., 2013. Continuous monitoring of summer surface water vapor isotopic composition above the Greenland ice sheet. Atmospheric Chemistry and Physics 13, 4815-4828. doi:10.5194/acp-13-4815-2013.

Steen-Larsen, H.C., Sveinbjörnsdottir, A.E., Jonsson, T., Ritter, F., Bonne, J.L., Masson-Delmotte, V., Sodemann, H., Blunier, T., Dahl-Jensen, D., Vinther, B.M., 2015. Moisture sources and synoptic to seasonal variability of North Atlantic water vapor isotopic composition. Journal of Geophysical Research: Atmospheres 120, 5757-5774. doi:10.1002/2015JD023234.

Steen-Larsen, H.C., Sveinbjörnsdottir, A.E., Peters, A.J., Masson-Delmotte, V., Guishard, M.P., Hsiao, G., Jouzel, J., Noone, D., Warren, J.K., White, J.W.C., 2014b. Climatic controls on water vapor deuterium excess in the marine boundary layer of the North Atlantic based on 500 days of in situ, continuous measurements. Atmospheric Chemistry and Physics 14, 77417756. doi:10.5194/acp-14-7741-2014.

Strong, M., Sharp, Z.D., Gutzler, D.S., 2007. Diagnosing moisture transport q using $\mathrm{D} / \mathrm{H}$ ratios of water vapor. Geophysical Research Letters 34. doi: 10 . 1029/2006GL028307.

${ }_{690}$ Tremoy, G., Vimeux, F., Mayaki, S., Souley, I., Cattani, O., Risi, C., Favreau, 
G., Ö̈, M., 2012. A 1-year long?18o record of water vapor in Niamey (Niger) reveals insightful atmospheric processes at different timescales. Geophysical Research Letters 39. doi $10.1029 / 2012$ GL051298.

Tremoy, G., Vimeux, F., Soumana, S., Souley, I., Risi, C., Favreau, G., Monique, O., 2014. Clustering mesoscale convective systems with laser-based water vapor $\delta 18 \mathrm{O}$ monitoring in Niamey (Niger). Journal of Geophysical Research: Atmospheres 119, 5079-5103. doi 10.1002/2013JD020968

Tsujimura, M., Sasaki, L., Yamanaka, T., Sugimoto, A., Li, S.G., Matsushima, D., Kotani, A., Saandar, M., 2007. Vertical distribution of stable isotopic composition in atmospheric water vapor and subsurface water in grassland n and forest sites, eastern Mongolia. Journal of Hydrology 333, 35 - 46. doi:10. 1016/j.jhydrol.2006.07.025

Uemura, R., Matsui, Y., Yoshimura, K., Motoyama, H., Yoshida, N., 2008. Evidence of deuterium excess in water vapor as an indicator of ocean surface conditions. Journal of Geophysical Research: Atmospheres 113. doi 10.1029/ 2008JD010209.

Wei, Z., Yoshimura, K., Okazaki, A., Kim, W., Liu, Z., Yokoi, M., 2015. Partitioning of evapotranspiration using high-frequency water vapor isotopic measurement over a rice paddy field. Water Resources Research doi:10.1002/2014WR016737.

Welp, L.R., Lee, X., Griffis, T.J., Wen, X.F., Xiao, W., Li, S., Sun, X., Hu, Z., Val Martin, M., Huang, J., 2012. A meta-analysis of water vapor deuteriumexcess in the midlatitude atmospheric surface layer. Global Biogeochemical Cycles 26. doi $10.1029 / 2011 \mathrm{~GB} 004246$

${ }_{715}$ Welp, L.R., Lee, X., Kim, K., Griffis, T.J., Billmark, K.A., Baker, J.M., 2008. $\delta 18 \mathrm{O}$ of water vapour, evapotranspiration and the sites of leaf water evap- 
oration in a soybean canopy. Plant, Cell and Environment 31, 1214-1228. doi $10.1111 / \mathrm{j} .1365-3040.2008 .01826 . \mathrm{x}$.

Wen, X.F., Zhang, S.C., Sun, X.M., Yu, G.R., Lee, X., 2010. Water vapor and precipitation isotope ratios in beijing, china. Journal of Geophysical Research: Atmospheres 115. doi:10.1029/2009JD012408.

Worden, H.M., Logan, J.A., Worden, J.R., Beer, R., Bowman, K., Clough, S.A., Eldering, A., Fisher, B.M., Gunson, M.R., Herman, R.L., Kulawik, S.S., Lampel, M.C., Luo, M., Megretskaia, I.A., Osterman, G.B., Shephard, M.W., 2007. Comparisons of tropospheric emission spectrometer (TES) ozone profiles to ozonesondes: Methods and initial results. Journal of Geophysical Research: Atmospheres 112. doi:10.1029/2006JD007258.

Yakir, D., Sternberg, L., 2000. The use of stable isotopes to study ecosystem gas exchange. Oecologia 123, 297-311. doi 10.1007/s004420051016.

Yoshimura, K., Kanamitsu, M., 2009. Specification of external forcing for regional model integrations. Monthly Weather Review 137, 1409-1421. doi:10.1175/2008MWR2654.1.

Yoshimura, K., Kanamitsu, M., Noone, D., Oki, T., 2008. Historical isotope simulation using reanalysis atmospheric data. Journal of Geophysical Research: Atmospheres 113. doi:10.1029/2008JD010074.

Yoshimura, K., Miyoshi, T., Kanamitsu, M., 2014. Observation system simulation experiments using water vapor isotope information. Journal of Geophysical Research: Atmospheres 119, 7842-7862. doi 10.1002/2014JD021662.

Yoshimura, K., Oki, T., Ohte, N., Kanae, S., 2004. Colored Moisture analysis estimates of variations in 1998 Asian monsoon water sources. Journal of the 
Meteorological Society of Japan. Ser. II 82, 1315-1329. doi:10.2151/jmsj.

2004.1315 

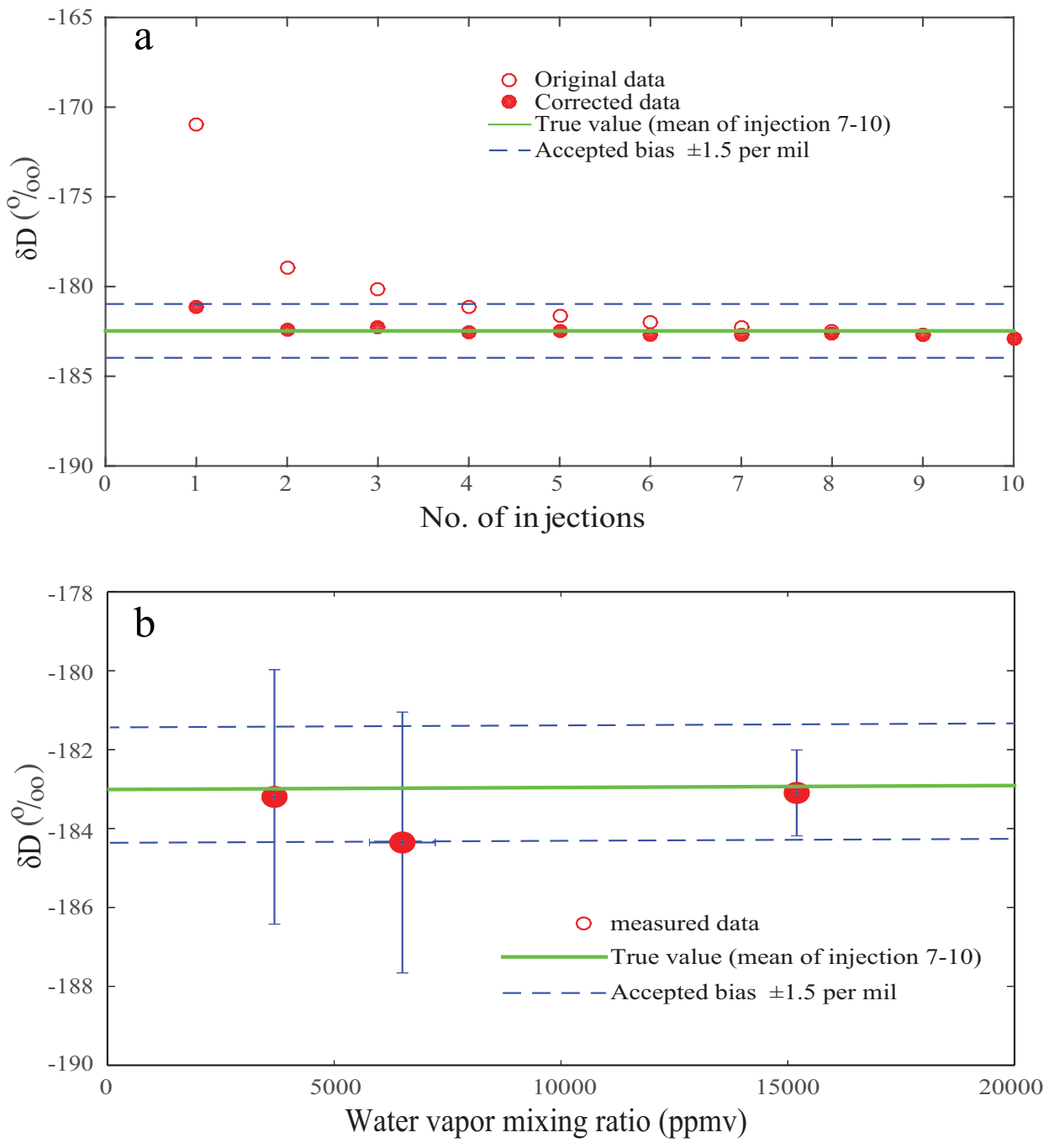

Figure 1: Calibration of water vapor and precipitation data (a). An example of correction procedure van Geldern and Barth, 2012) to reduce memory effect in precipitation isotopic analysis. All the injections of a sample can be used after correction and the number of rejections per unknown can be reduced to 4 . After correction, four injections of each sample were averaged and normalized to the VSMOW/SLAP scale by using a two-point linear calibration. (b). Evaluation of the dependency of the measured isotopic value on water vapor concentration by injecting different amounts of standard water into the vaporizer. Three tests have been done in field conditions, during 2013/09/01-2013/09/02 $(Q=15200 \pm 200 \mathrm{ppmv}, \delta D=183.1 \pm 1.1 \%$, Total number $n=1516), 2014 / 09 / 16-2014 / 09 / 17 \quad(Q=6500 \pm 700$ ppmv, $\delta D=184.3 \pm 3.3 \%$, $n=2109)$ and $2015 / 03 / 31-2015 / 04 / 01(Q=3700 \pm 100 \mathrm{ppmv}, \delta D=183.2 \pm 3.2 \% 0, n=1136)$. 

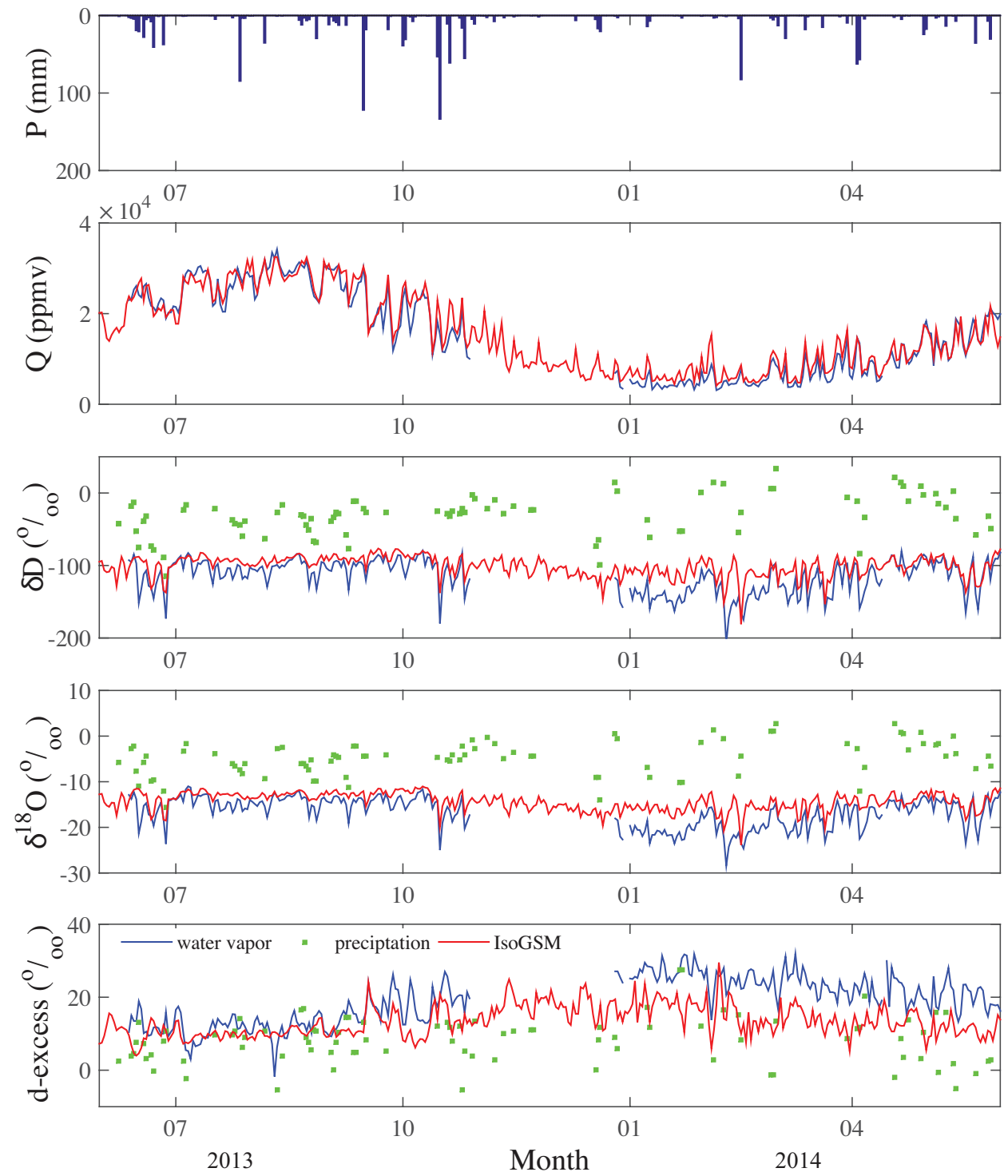

Figure 2: Time series of daily observation in precipitation amount $(P)$, vapor mixing ratios $(Q)$, water vapor and precipitation $\delta^{18} O, \delta D$ and $d$-excess (blue line for tower observations, green square for precipitation). The red lines represent the simulated water vapor mixing ratio and water vapor isotope ratios at $2-\mathrm{m}$ level by IsoGSM. 

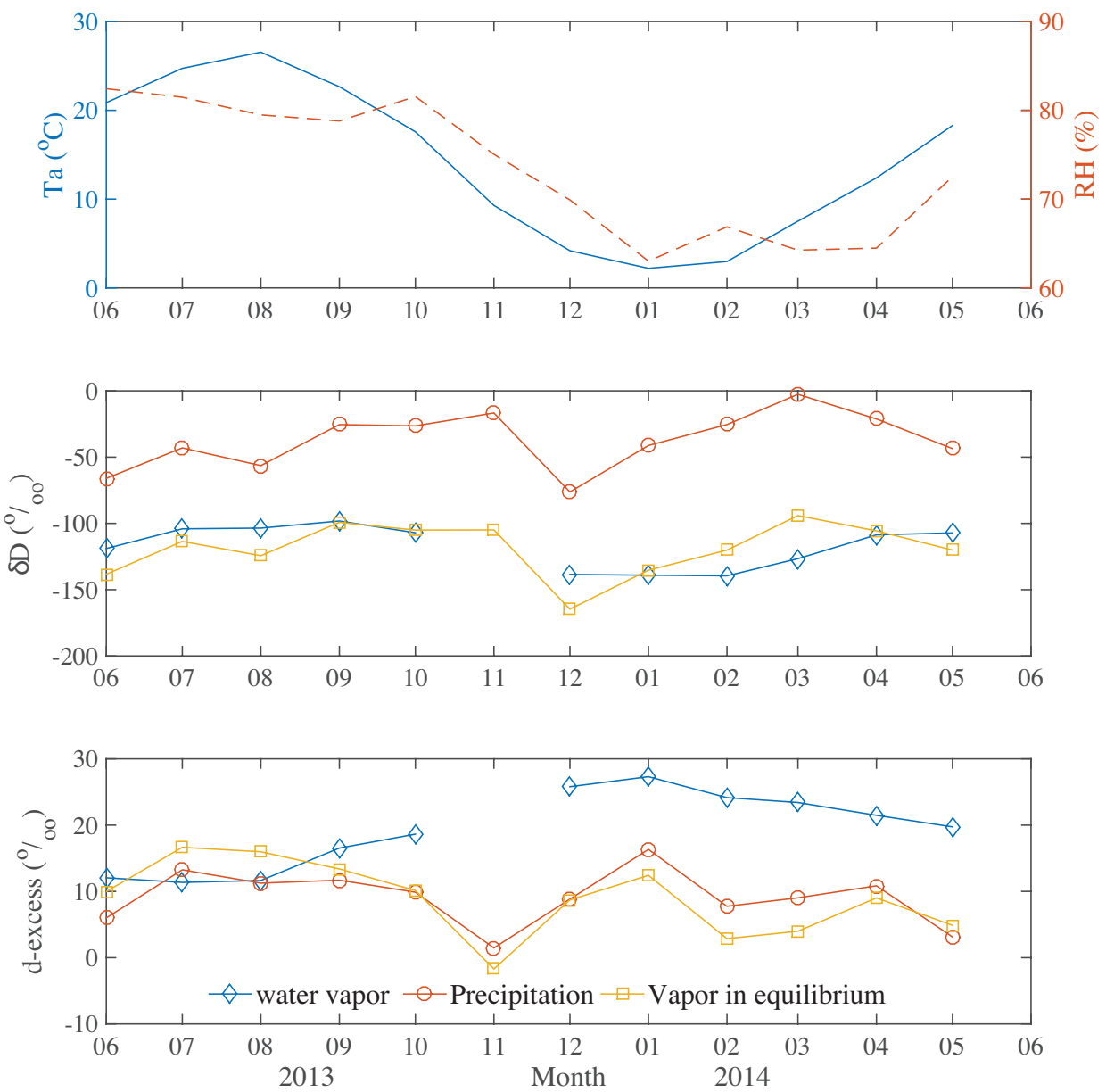

Figure 3: Monthly averaged relative humidity $\left(R H\right.$, dash), Temperature ( $T_{a}$, solid), isotope ratio $\delta D, d$-excess of water vapor (diamond)and precipitation (circle). Water vapor isotope $\delta D_{v, e}$ and $d_{v, e}-$ excess predicted from precipitation (square) are also plotted. 


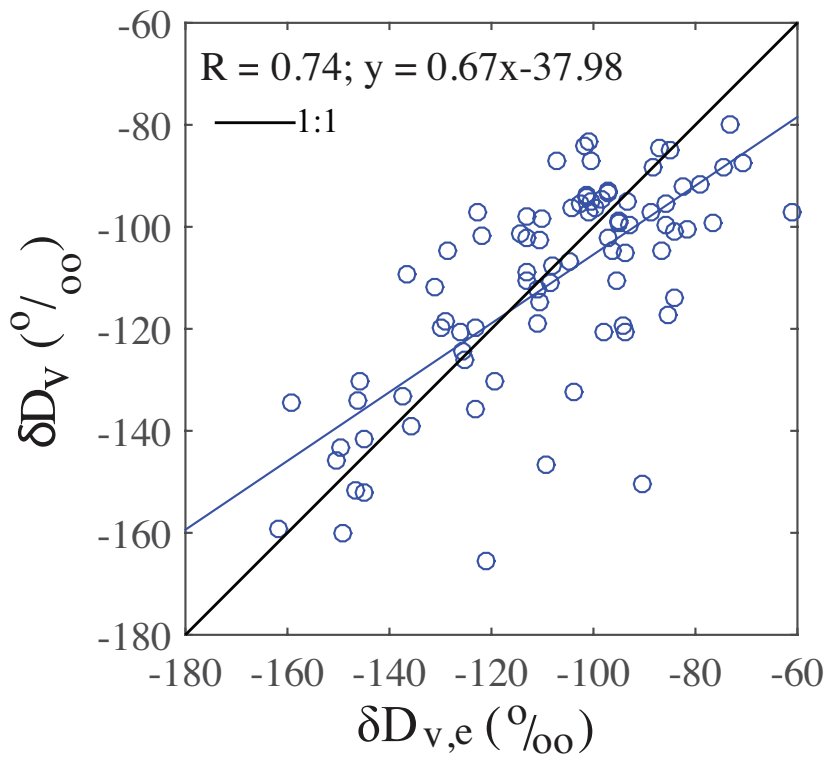

Figure 4: Comparison between the observed water vapor $\delta D_{v}$ and precipitation predicted $\delta D_{v, e}$. Each point represents a rainy day. 


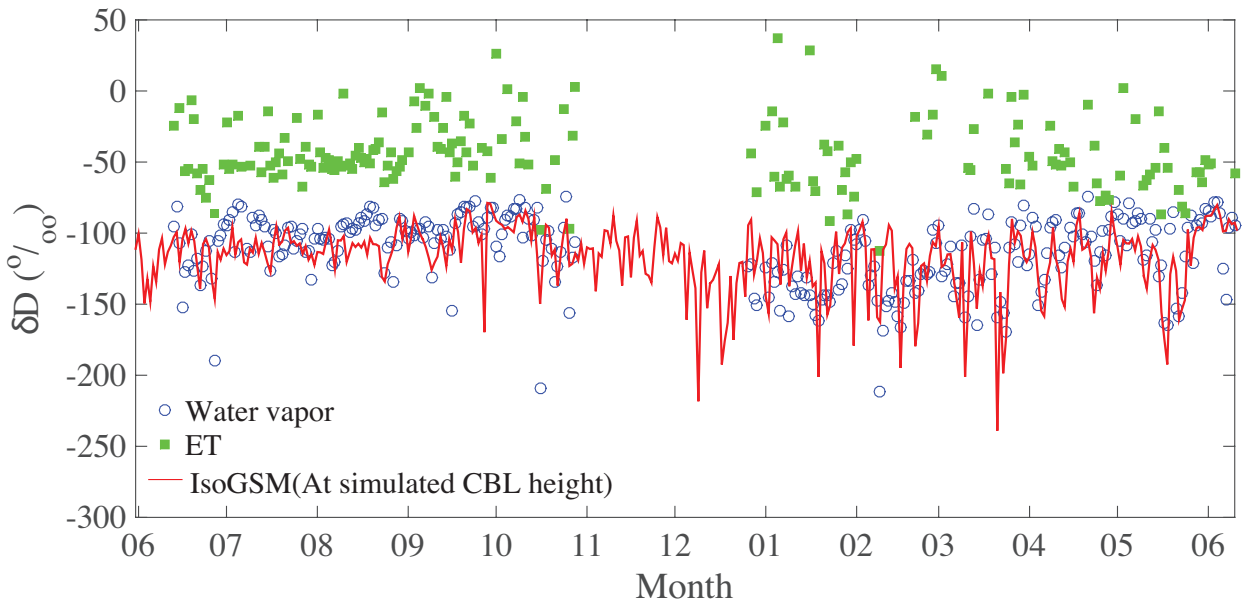

Figure 5: Daily variation of isotope ratios of evapotranspiration (green filled square, excluded rainy days), water vapor (blue unfilled circle, excluded rainy days) and background derived from IsoGSM simulation. 


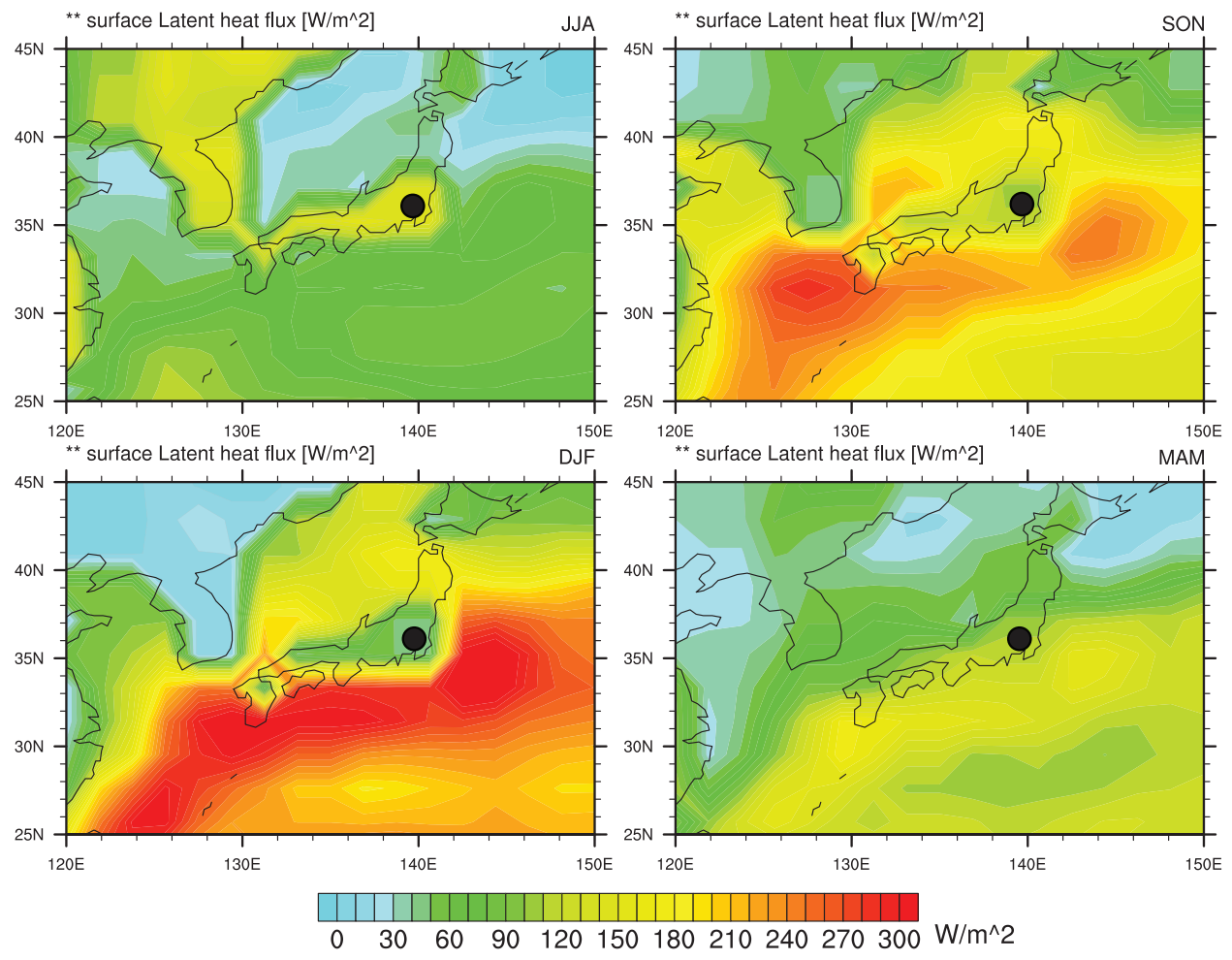

Figure 6: IsoGSM simulated seasonal mean latent heat fluxes. Black dot shows the study site 

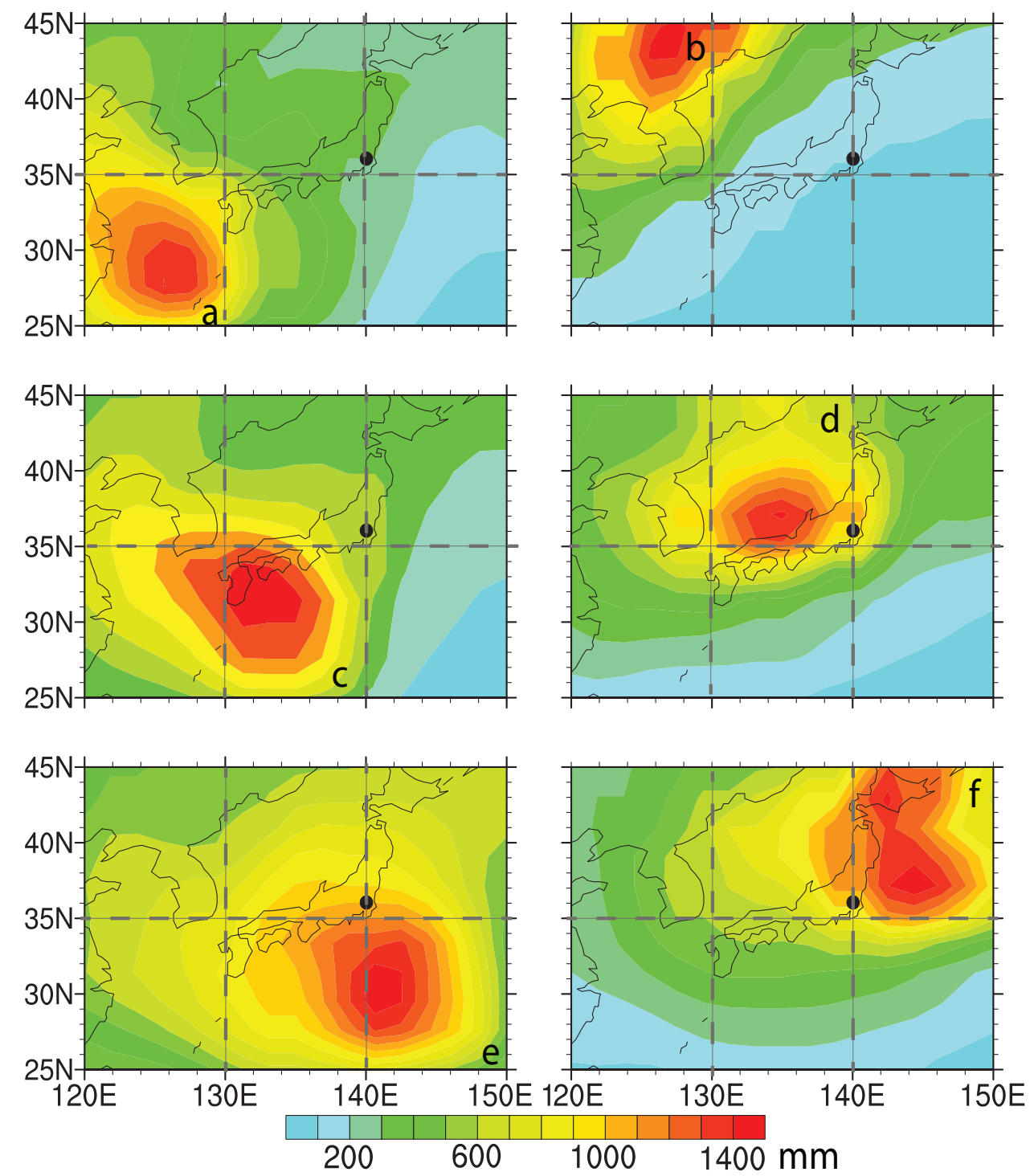

Figure 7: The atmospheric column precipitable water contributed from tagged boxes in JJA. Source regions for tagging experiments of water vapor tagged within $10 \times 10$ degree boxes (contour): a, 25N-35N, 120E-130E; b,35N-45N, 120E-130E; c, 25N-35N, 130E-140E; d, 35N$45 \mathrm{~N}, 130 \mathrm{E}-140 \mathrm{E}$; e, $25 \mathrm{~N}-35 \mathrm{~N}, 140 \mathrm{E}-150 \mathrm{E}$; f, 35N-45N, $140 \mathrm{E}-150 \mathrm{E}$. 


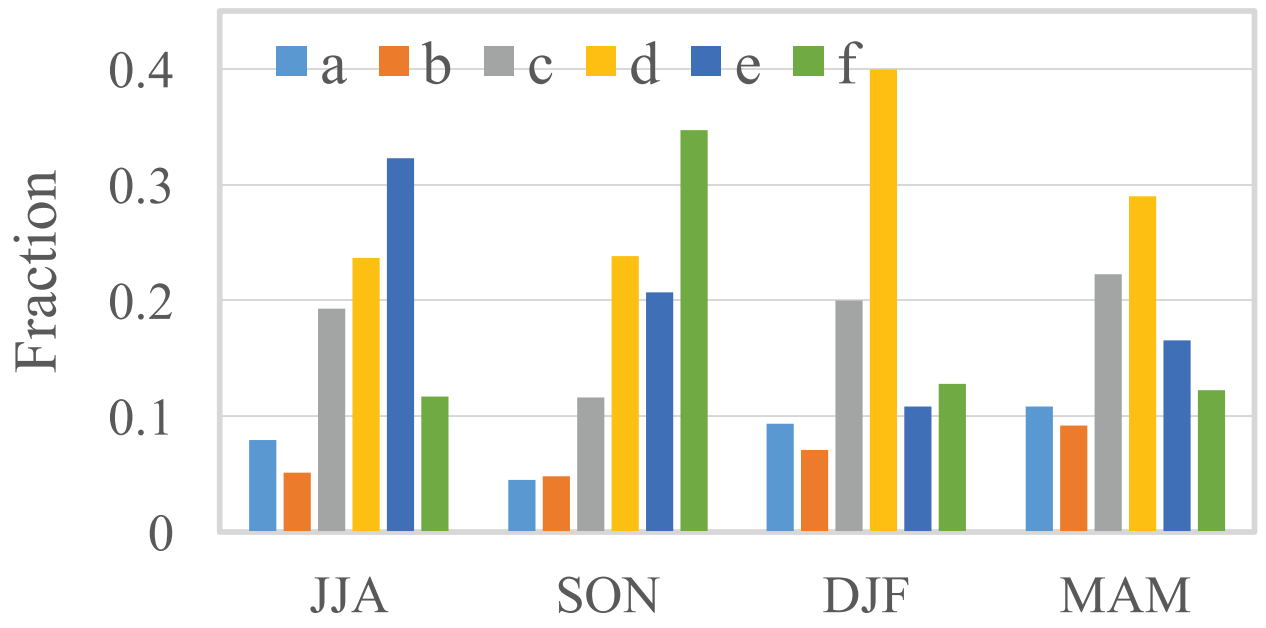

Figure 8: The contribution fraction from tagged boxes in JJA, SON, DJF and MAM. 


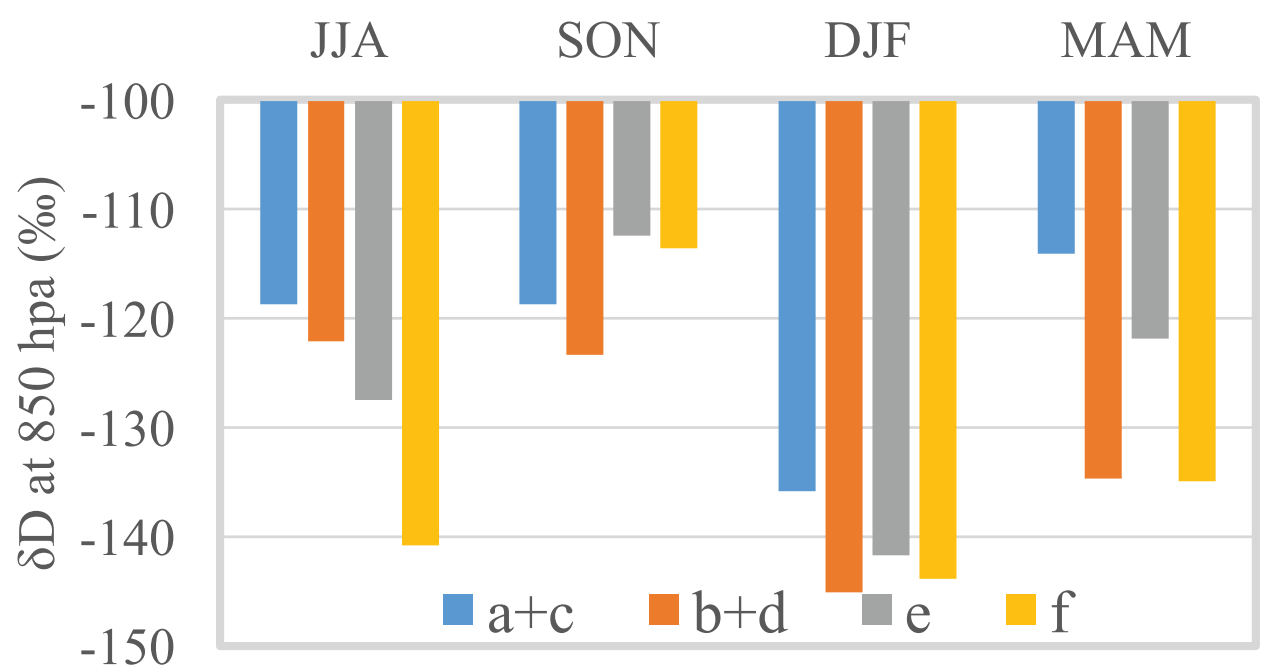

Figure 9: $850 \mathrm{hpa}$ isotope ratios documented based on the wind direction $\left(0^{\circ}\right.$ to $90^{\circ}$, Area f; $90^{\circ}$ to $180^{\circ}$, Area e; $180^{\circ}$ to $270^{\circ}$, Area $\mathrm{a}+\mathrm{c} ; 270^{\circ}$ to $360^{\circ}$, Area b+d). 


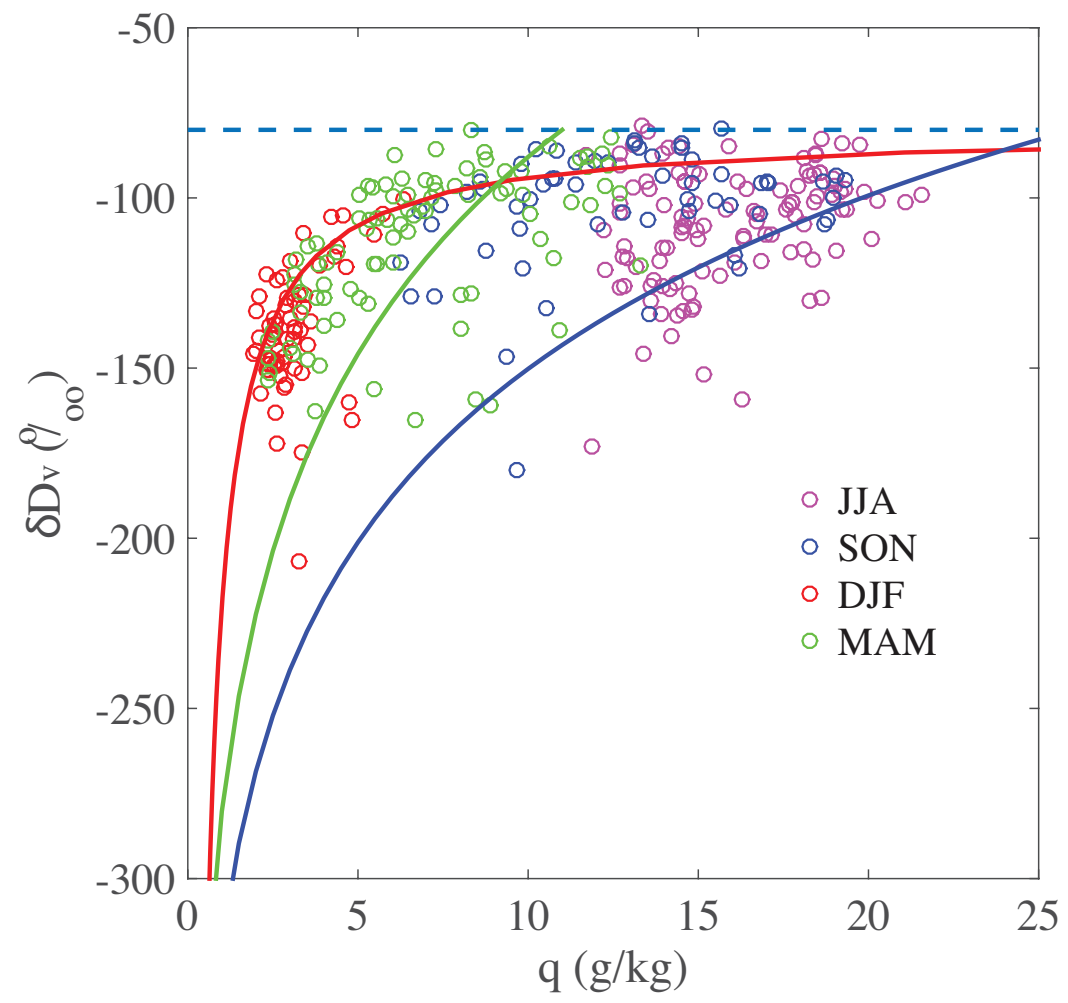

Figure 10: The variation of hourly water vapor $\delta D$ as a function of specific humidity $q$ for JJA, SON, DJF and MAM. Rayleigh distillation curves representing a pseudoadiabatic process based on oceanic temperatures with an initial $\delta D$ values of $-80 \%$ (approximate value of vapor in equilibrium with ocean, shown as blue dash line) are shown as green solid line $\left(15^{\circ} \mathrm{C}\right)$ and blue solid line $\left(25^{\circ} \mathrm{C}\right)$. The red line called Evaporation line represents a special case where the source water is the infinite reservoir of vapor that is in thermodynamic equilibrium (i.e., saturated) with the ocean surface. 


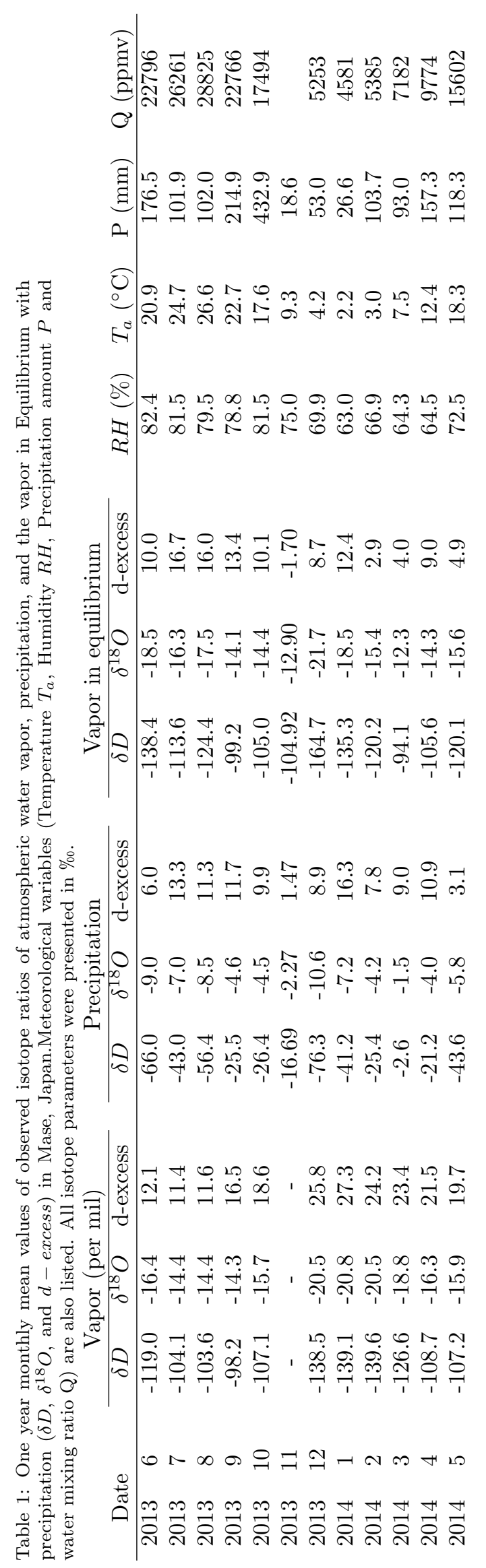


Table 2: The contribution of evapotranspiration $\left(F_{E T}\right)$ to that of the ABL water vapor estimated from monthly water vapor $\delta D$, background isotope ratio $\delta_{b g}$ and evapotranspiration isotope ratio $\delta_{E T}$. Data from rainy days, data of latent heat $L E<50 \mathrm{~W} / \mathrm{m}^{2}$ and daily $F_{E T}$ $<0$ data were excluded. All isotope parameters presented in \%o.

\begin{tabular}{cccccc} 
Year & Month & $\delta D_{v}$ & $\delta_{b g}$ & $\delta_{E T}$ & $F_{E T}$ \\
\hline 2013 & 6 & -99.6 & -109.7 & -56.9 & $19.2 \pm 14.0 \%$ \\
2013 & 7 & -96.3 & -111.1 & -45.7 & $22.7 \pm 13.6 \%$ \\
2013 & 8 & -97.8 & -110.3 & -46.8 & $19.7 \pm 11.1 \%$ \\
2013 & 9 & -92.8 & -107.4 & -31.0 & $19.1 \pm 12.5 \%$ \\
2013 & 10 & -89.7 & -94.6 & -36.3 & $8.4 \pm 10.6 \%$ \\
2013 & 11 & - & - & - & - \\
2013 & 12 & - & - & - & - \\
2014 & 1 & -148.7 & -149.7 & -91.7 & $0.2 \pm 13.1 \%$ \\
2014 & 2 & -124.3 & -143.6 & 9.7 & $12.6 \pm 13.4 \%$ \\
2014 & 3 & -115.2 & -123.8 & -49.5 & $0.11 \pm 8.3 \%$ \\
2014 & 4 & -106.4 & -124.5 & -51.8 & $24.9 \pm 12.7 \%$ \\
2014 & 5 & -117.2 & -131.1 & -62.5 & $20.2 \pm 14.2 \%$ \\
\hline
\end{tabular}

